Article

\title{
Archaeological Surveying of Subarctic and Arctic Landscapes: Comparing the Performance of Airborne Laser Scanning and Remote Sensing Image Data
}

\author{
Alma Elizabeth Thuestad ${ }^{1, *}\left(\mathbb{D}\right.$, Ole Risbøl $^{2}\left(\mathbb{D}\right.$, Jan Ingolf Kleppe ${ }^{3}$, Stine Barlindhaug ${ }^{4}$ and Elin Rose Myrvoll ${ }^{4}$ \\ 1 High North Department, Norwegian Institute for Cultural Heritage Research (NIKU), Fram Centre, \\ N-9296 Tromsø, Norway \\ 2 Department of Archaeology and Cultural History, Norwegian University of Science and Technology, \\ N-7491 Trondheim, Norway; ole.risbol@ntnu.no \\ 3 Troms and Finnmark County Council, Fylkeshuset, N-9815 Vadsø, Norway; jan.ingolf.kleppe@tffk.no \\ 4 Sámediggi-The Sami Parliament, N-9735 Karasjok, Norway; stine.barlindhaug@samediggi.no (S.B.); \\ elin.rose.myrvoll@samediggi.no (E.R.M.) \\ * Correspondence: alma.thuestad@niku.no; Tel.: +47-908-56-303
}

check for

updates

Citation: Thuestad, A.E.; Risbøl, O.; Kleppe, J.I.; Barlindhaug, S.; Myrvoll, E.R. Archaeological Surveying of Subarctic and Arctic Landscapes: Comparing the Performance of Airborne Laser Scanning and Remote Sensing Image Data. Sustainability 2021, 13, 1917. https://doi.org/ $10.3390 /$ su13041917

Academic Editor: Alin Mihu-Pintilie

Received: 15 December 2020

Accepted: 4 February 2021

Published: 10 February 2021

Publisher's Note: MDPI stays neutral with regard to jurisdictional claims in published maps and institutional affiliations.

Copyright: (c) 2021 by the authors. Licensee MDPI, Basel, Switzerland. This article is an open access article distributed under the terms and conditions of the Creative Commons Attribution (CC BY) license (https:// creativecommons.org/licenses/by/ $4.0 /)$.
Abstract: What can remote sensing contribute to archaeological surveying in subarctic and arctic landscapes? The pros and cons of remote sensing data vary as do areas of utilization and methodological approaches. We assessed the applicability of remote sensing for archaeological surveying of northern landscapes using airborne laser scanning (LiDAR) and satellite and aerial images to map archaeological features as a basis for (a) assessing the pros and cons of the different approaches and (b) assessing the potential detection rate of remote sensing. Interpretation of images and a LiDARbased bare-earth digital terrain model (DTM) was based on visual analyses aided by processing and visualizing techniques. 368 features were identified in the aerial images, 437 in the satellite images and 1186 in the DTM. LiDAR yielded the better result, especially for hunting pits. Image data proved suitable for dwellings and settlement sites. Feature characteristics proved a key factor for detectability, both in LiDAR and image data. This study has shown that LiDAR and remote sensing image data are highly applicable for archaeological surveying in northern landscapes. It showed that a multi-sensor approach contributes to high detection rates. Our results have improved the inventory of archaeological sites in a non-destructive and minimally invasive manner.

Keywords: cultural heritage; LiDAR; satellite image; aerial image; High North

\section{Introduction}

Remote sensing has become a very valuable resource for modern archaeology as a useful tool for finding and documenting cultural heritage sites. Airborne laser scanning (LiDAR hereafter) and aerial and satellite image data are well established and highly applicable approaches to find and study sites in a non-destructive and minimally invasive manner. Archaeological application of remote sensing data is, however, rarely a straightforward process, and considerable efforts have been put into developing and improving methodological approaches. The pros and cons of different remote sensing data vary and, accordingly, so do areas of utilization and methodological approaches applicable for analysing the data. Other complicating factors are the multitude and variety of archaeological sites and the wide range of natural environments in which they are located.

The northernmost part of Norway has been surveyed for archaeological sites by researchers and management authorities since the early 1920s [1-3]. Survey efforts henceforth focused primarily on coastal and riverine areas as well as other relatively easily accessible areas. Extensive areas, especially in the interior, are thus yet to be systematically surveyed. Consequently, there is a significant disparity in the number of known archaeological sites in inland and coastal areas, as can be seen in Figure 1. Survey projects conducted in inland 
areas in recent decades have highlighted the fact that this distribution pattern is not representative of prehistoric activity in this region [4]. There is thus a need to utilize data and methodological approaches that allow remote and hard-to-get-to areas to be surveyed in a low-impact and cost-efficient manner.

A characteristic of cultural heritage in the subarctic and arctic landscapes of Northern Norway is that traces of past human activity are often directly visible on the surface. Sparse vegetation cover, slow regrowth, a relative absence of modern infrastructure and low agricultural activity are factors that have allowed for preservation of sites from the pioneer settlement up until modern times. Remote sensing utilizing LiDAR data and satellite and aerial images has a great potential for improving the inventory of known archaeological sites throughout the region.

The aim of this study is to assess and compare the applicability of LiDAR and remote sensing image data for archaeological surveying in the subarctic and arctic landscapes of Northern Norway. High-resolution satellite images, digital aerial photographs and LiDAR data are used to identify and map potential archaeological features as a basis for (a) assessing the pros and cons of the different approaches, and (b) assessing the potential detection rate of remote sensing in northern landscapes.

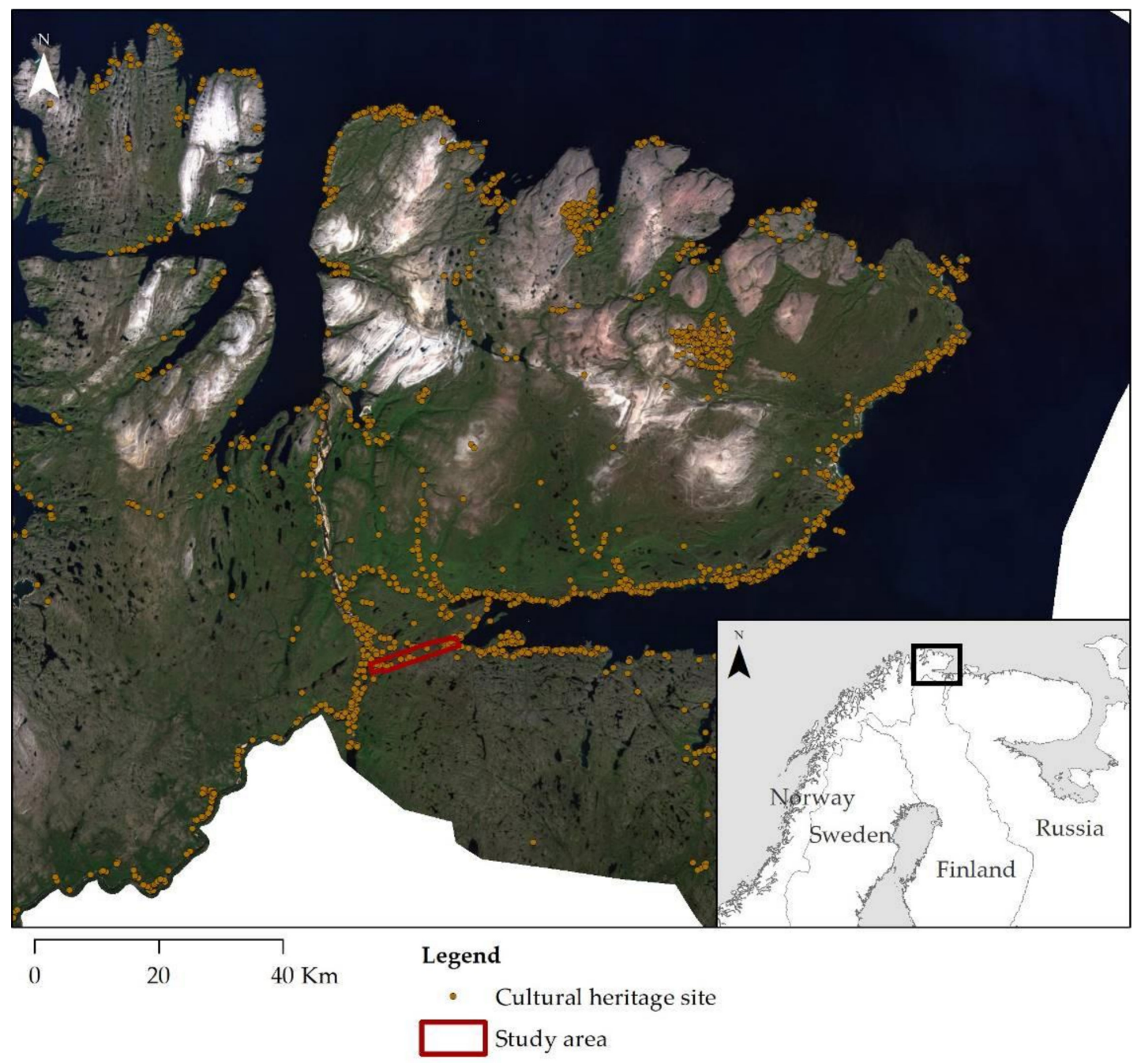

Figure 1. Cultural heritage sites listed in the national cultural heritage database Askeladden in December 2020, here marked in amber, in and around the Varanger Peninsula in northern- and easternmost Norway. The $25 \mathrm{~km}^{2}$ large study area, here outlined in red, is located on an isthmus between a river and the inner part of the fjord just south of the Varanger Peninsula. Image (Norwegian Mapping Authority. 
Remote sensing is not a new concept in archaeology [5]. In Norway, systematic use of remote sensing for archaeological purposes began in the early 1960s in conjunction with a large national state-funded survey project conducted between 1960 and 1991. Aerial photographs were then used as base maps for delineating cultural heritage and as a basis for producing Norwegian Public Land Use Maps. The actual surveys were ground-based and conducted through traditional means [6].

Remote sensing platforms, having grown increasingly sophisticated, now offer significantly finer spatial and spectral resolutions than previously available, coincidentally providing data that are progressively more useful for archaeological purposes. Initial examples of archaeological applications of satellite images in Norway used Landsat images with $30 \mathrm{~m}$ resolution [7]. Image data are highly useful for monitoring vegetation changes and have proven suitable for assessing subsequent impact on cultural heritage. Landsat data (Landsat 5 Thematic Mapper (TM) and 7 Enhanced Thematic Mapper (ETM+)) with a spatial resolution of $28.5 \mathrm{~m}$ were used to show impact on archaeological features through regrowth and reforestation brought on by farm abandonment in Northern Norway $[7,8]$. In Northern Norway, Quickbird-2 image data (available from DigitalGlobe, a subsidiary of Maxar Technologies, Longmont, CO, USA) with $0.6 \mathrm{~m}$ (panchromatic image) and $2.4 \mathrm{~m}$ (multispectral image) resolution enabled detection of maintained and abandoned reindeer pens, milking pens and dwellings linked to Sámi reindeer husbandry [9].

Archaeological use of remote sensing image data encompasses quantitative and qualitative techniques and often a combination thereof. Visual analyses, alone or in combination with image enhancement techniques or semi-automatic procedures, have proven useful for detecting surface and subsurface archaeological features, especially large-scale features [10]. Image processing techniques are a valuable contribution as they serve to enhance the interpretability of data by enhancing spatial patterns or local anomalies linked to past human activities [11-13]. Effective automatic procedures have proven challenging for archaeological purposes, but semi-automatic approaches and enhancement techniques work quite well, keeping in mind that their performance has proven somewhat "site specific" and "feature specific" $[12,14]$. In Norway, a semi-automatic detection methodology was developed and implemented through the CultSearcher software developed by the Norwegian Computing Center (Oslo, Norway) in the early 2000s [15,16]. It was initially based on satellite image data, but the focus has since been directed more towards semi-automatic detection based on LiDAR data [17]. The system detects potential archaeological features, and accordingly, verification is dependent on field surveys. The use of remote sensing image data has proven most successful when archaeological sites are located in landscapes with a relatively uniform topography and vegetation cover. For instance, features located in arable land or marl landscapes appear as anomalies in an otherwise uniform image [16,18].

LiDAR has been available to the archaeological community since the beginning of the millennium [19]. It is an active method which collects data from the ground using laser pulses, rendering it possible to collect very detailed information about the earth surface, which can be used to create high resolution 3D representations of the topography. An important aspect is the ability to classify the collected data in ground and off-ground data, enabling the elimination of laser points bouncing off vegetation, the top of buildings, etcetera and leaving the user with a "bare-earth" model. LiDAR has, due to this principal advantage, gained interest among archaeologists involved in mapping cultural heritage [20]. A main objective of many early studies was to test the suitability of LiDAR in different landscapes and with regard to the type of archaeology specific for the region worked in. LiDAR has proven effective for identifying regularly shaped archaeological features such as burial mounds, charcoal kilns, hunting pits, etcetera [21,22]. Further work has concentrated on elucidating the detection success of mapping cultural heritage within a given area [22,23]. Another field of interest has been different visualising techniques aimed at improving the detection success [24-27], followed by studies comparing different visualising techniques. The results generally point towards the conclusion that one will benefit from using various techniques on the same data set [28-30]. 


\section{Study Area and Cultural Historical Background}

\subsection{Study Area}

The $25 \mathrm{~km}^{2}$ large study area is located on an isthmus in the easternmost part of Northern Norway. The area encompasses inland mountainous and lowland landscapes as well as coastal landscapes. According to land resource maps [31] the area outlined in Figure 1 encompasses forested areas $(47.3 \%)$, mountainous and other areas without vegetation $(17.7 \%)$, marshes and moorland $(32.6 \%)$, agricultural areas $(1.1 \%)$, freshwater rivers and lakes $(1 \%)$ and ocean $(0.3 \%)$.

The area is located in a region with a rich cultural heritage going back to the pioneer settlement following the retreat of the ice cap at end of the last Ice Age. The area was selected precisely because it encompasses a large number of cultural heritage sites and features typical for the region, and because it is an area with a very high potential for so far unknown or unlisted sites. The latter is especially true for the inland part of the area. A primary focus of this study is therefore on the inland areas, which are also less disturbed by modern activity than the coastal areas.

\subsection{Cultural Historical Background}

Human presence in Northern Norway extends back around 12,000 years. As ice melted and withdrew after the last glacial period, archaeological evidence shows that ice-free areas were quite rapidly inhabited [32,33]. The older prehistory of the region is divided into three periods characterized by different technologies and social organization: The Early Stone Age (10,000-4500 BC), the Late Stone Age (4500-1800 BC) and the Early Metal Age (1800 BC-BC). Latter prehistory is designated the Iron Age (0-1100 AD) and the Medieval period (1100-1600 AD). Throughout prehistory, well into historic times, nomadic or semipermanent settlement based on hunter-gathering, fishing and reindeer herding have been predominant [34].

The inlands of the region where the study area is located is especially known for numerous hunting pit systems reminiscent of early reindeer hunting, and the coastal areas for the multitude settlement traces ranging from the Stone Age to historic times.

Numerically speaking, in the northernmost part of Norway, hunting pits are the most common category of archaeological feature listed in Askeladden, the national cultural heritage database [35]. Hunting pits most often appear as up to $1.5 \mathrm{~m}$ deep and 2-5 m wide circular or oval depressions, normally surrounded by a low wall of soil (see Figure 2 for examples). Although disputed due to methodological challenges when dating hunting pits, excavations have yielded dates covering a time span of almost 4000 years from the Late Stone Age to AD 1600 [36-39]. Pits are found throughout Northern Norway, but numbers are highest in inner fjord areas and inland areas along major rivers [36,40,41]. Other features commonly linked to wild reindeer hunting are hunting blinds and leading fences. The high numbers and widespread distribution are indicative of the importance of reindeer hunting from the Stone Age to Sámi subsistence and economy [42,43].

Settlement sites dating to the Late Stone Age and Early Metal Age are often identified through the still visible remains of dwelling structures (see Figure 3 for examples). Sites may encompass anywhere from one dwelling to several tens. The dwellings, which may be slightly dug into the ground, are circular or rectangular structures ranging in size from around $10 \mathrm{~m}^{2}$ to $70 \mathrm{~m}^{2}$. Sámi sites, the oldest going back around 2500 years, commonly encompass camp sites and dwelling remains in the form of circular and rectangular tur houses. 


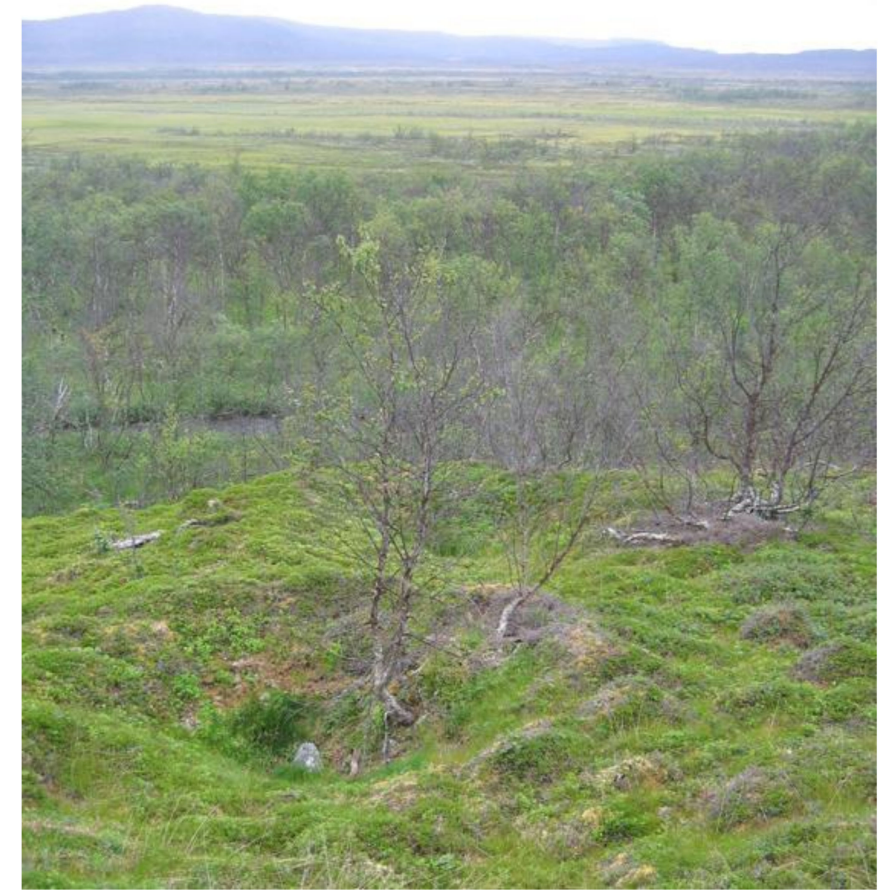

Figure 2. Hunting pits for wild reindeer located in the study area during field work in 2008. Photo (C) Ole Risbøl, NTNU.

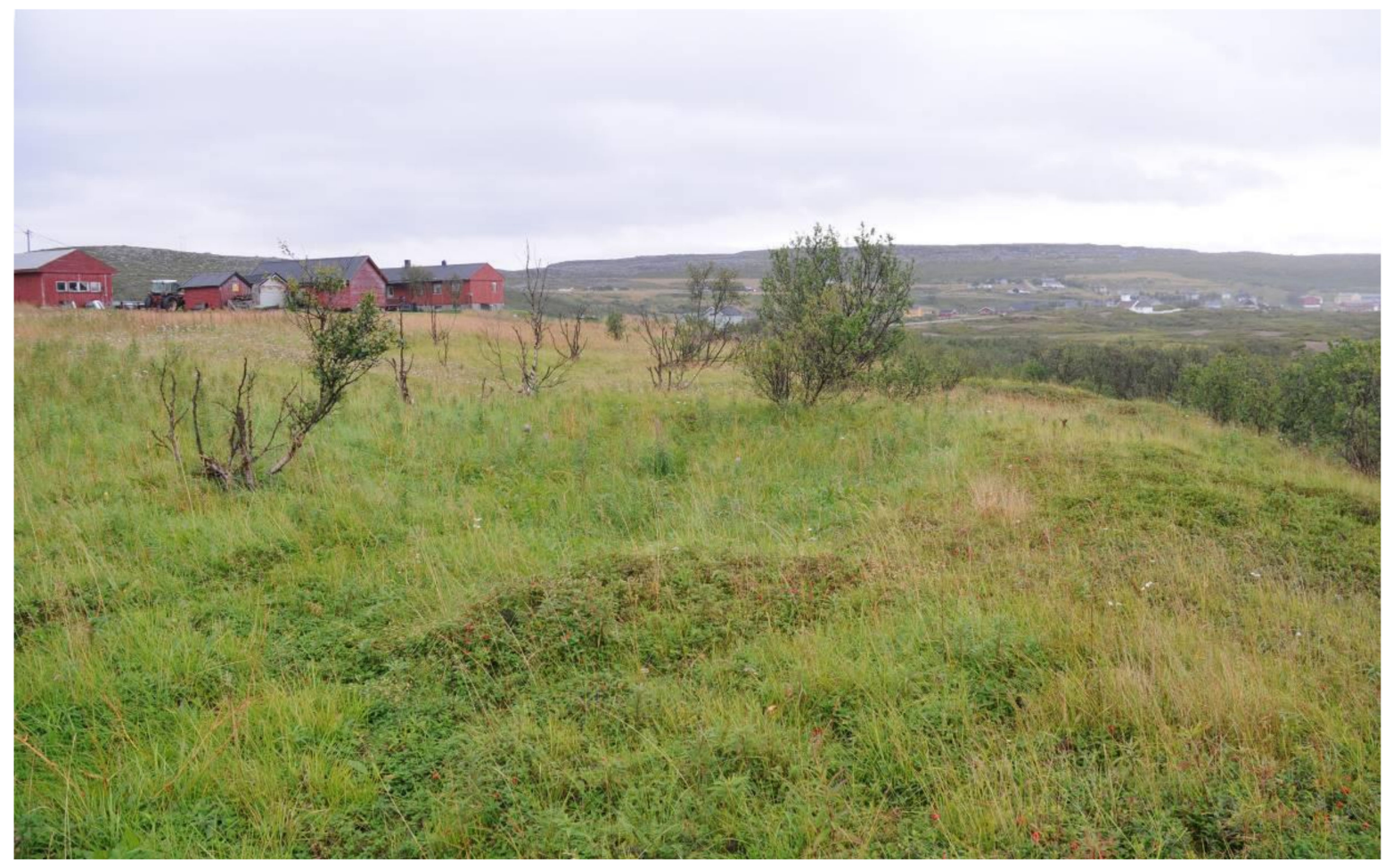

Figure 3. Settlement site with dwellings from the Late Stone Age located in the study area during field work. Photo $\odot$ Elin Rose Myrvoll, Sámediggi. 


\section{Materials and Methods}

\subsection{Satellite and Aerial Image Data}

Image data used in this study encompass WorldView 2 satellite data (DigitalGlobe, Longmont, CO, USA) and aerial images made available by the Norwegian Mapping Authority [44]. Interpretation was based on visual analyses aided by image processing techniques. WorldView-2 images (Table 1) and digital aerial photographs (Table 2) were analysed (see below) using ENVI 5.1 software (Exelis Visual Information Solutions, Inc., Broomfield, CO, USA, a subsidiary of Harris Corporation) and ArcGIS 10.4.1 software (ESRI ${ }^{\circledR}$ ArcMap ${ }^{\mathrm{TM}}$, Redlands, CA, USA).

Table 1. Metadata WorldView-2 image data.

\begin{tabular}{|c|c|}
\hline \multicolumn{2}{|c|}{ Satellite Image Data } \\
\hline Sensor & WorldView-2 \\
\hline Product Type: & Ortho Ready Standard 2A \\
\hline Product Option: & Bundle-multispectral ( 4 bands) and \\
\hline Acquisition Data (Y-M-D) & $2010-07-26$ \\
\hline \multirow[t]{3}{*}{ Cloud Cover $(\%)$} & 0 \\
\hline & Panchromatic: $0.450-0.800$ \\
\hline & Band 1 (Blue): $0.450-0.510$ \\
\hline \multirow[t]{3}{*}{ Wavelength $(\mu \mathrm{m})$} & Band 2 (Green): $0.510-0.580$ \\
\hline & Band 3 (Red): 0.630-0.690 \\
\hline & Band 4 (Near-infrared1): 0.770-0.895 \\
\hline Panchromatic Resolution & $0.5 \mathrm{~m}$ \\
\hline Multispectral Resolution & $2 \mathrm{~m}$ \\
\hline
\end{tabular}

Table 2. Metadata digital aerial images.

\begin{tabular}{ccc}
\hline & Aerial Image Data & \\
\hline Project $^{\mathbf{1}}$ & Finnmark 2010 & Sør-Varanger 2008 \\
\hline Sensor & Digital & Digital \\
Product Type: & Ortofoto 50 & Ortofoto 50 \\
Acquisition Data (Y-M-D) & $2010-09-10$ & $2008-09-15$ \\
Image Category & Colour $(24 \mathrm{bit} / \mathrm{px})$ & Colour $(24 \mathrm{bit} / \mathrm{px})$ \\
Resolution & $0.5 \mathrm{~m}$ & $0.5 \mathrm{~m}$ \\
\hline
\end{tabular}

${ }^{1}$ The study area is covered by part coverages acquired in 2008 and 2010.

The Gram-Schmidt pan-sharpening procedure using nearest neighbour resampling was utilized to spatially enhance the lower resolution satellite multispectral images, ensuring that all analysed images had a spatial resolution of $0.5 \mathrm{~m}$. Interpretation was aided by image enhancement functions available in ENVI, which served to improve interpretability by making subtle features more visible and increasing distinction between various features. Linear contrast enhancement was used, the histogram manipulated to increase contrast between potential features and the surrounds. Visual interpretation of the satellite images was based on both panchromatic and pan-sharpened multispectral images, which were analysed separately to assess whether the results differed significantly. Prior to the final analysis of the multispectral images, a variety of band combinations was tested to ascertain contrast. The final analyses were based on the following sequences: (a) bands 3, 2, 1 (Red-Green-Blue) and (b) bands 4, 3, 2 (Near-infrared1-Red-Green). The first sequence consists of the three primary colour bands red, green and blue (hereafter RGB) producing a so-called "true colour" image that closely resembles what would be observed by human eyes. The second sequence encompassing the near infrared, red and green band allows for vegetation and variations in vegetation linked to type and condition to be readily detected. The aerial images (see Figure 4 for example) were only available as RGB or "true colour".

Detected potential archaeological features were manually delineated at a 1:2000 resolution. 


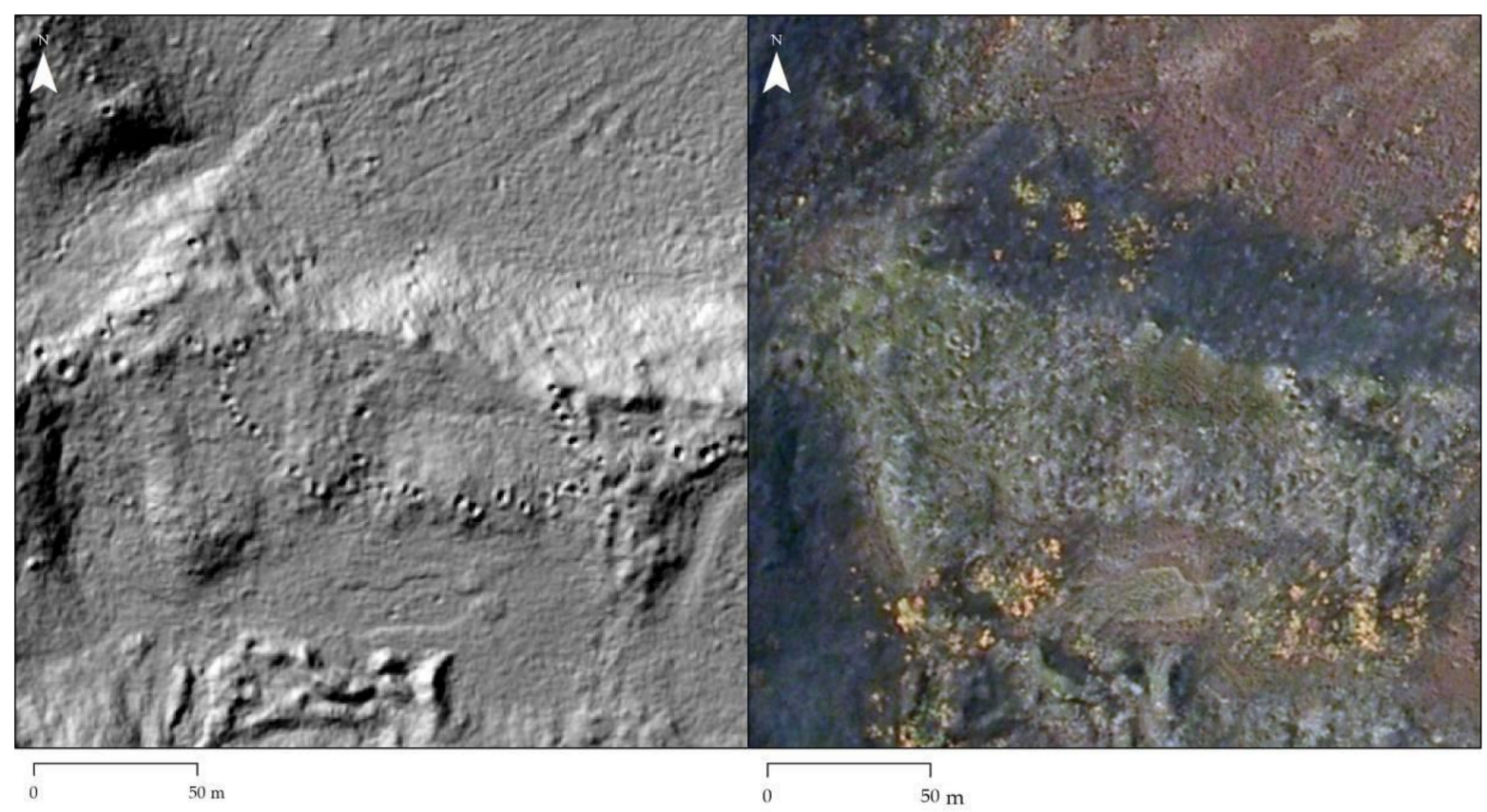

Figure 4. Two images of the same section of the study area; on the left, showing hunting pits in the digital terrain model (DTM) and, on the right, hunting pits in the aerial image. Image: (CNorwegian Mapping Authority.

\subsection{LiDAR Data}

Airborne laser scanning (see Table 3 for metadata) covering just over $30 \mathrm{~km}^{2}$ resulted in a total of 154 million collected points, of which 86 million were classified as ground points and 68 million as off-ground points. The average point density varied from 5 to 8 points per $\mathrm{m}^{2}$ with approximately 3 ground points per $\mathrm{m}^{2}$. The dataset was divided into 92 tiles covering $700 \times 700 \mathrm{~m}$ each. A $25 \mathrm{~km}^{2}$ large section of this dataset was used as a basis for the analyses in this study. The dataset was analysed and interpreted for the first time in 2007/2008 [23,45] and later used for new analyses carried out by Troms and Finnmark County during the period 2010-2020.

Table 3. Metadata airborne laser scanning (LiDAR).

\begin{tabular}{cc}
\hline Platform & Aircraft, Fix-Winged \\
\hline Acquisition data (Y-M) & $2007-09$ \\
Altitude & $1200 \mathrm{~m} \cdot$ a.g.1. \\
Flight speed & $75 \mathrm{~m} / \mathrm{s}$ \\
Pulse repetition frequency & $100 \mathrm{kHz}$ \\
Maximum scan angle & $\approx 3$ points per $\mathrm{m}^{2}$ \\
Delivery format & LAS \\
\hline
\end{tabular}

In the 2007/2008 study, a bare-earth digital terrain model (DTM hereafter) generated from the ground points constituted the base for analysis and interpretations. Generating the DTM as well as analysis and interpretations of the consecutive hill-shaded model was carried out using a 3D modelling software called Quick Terrain Modeler (hereafter QTM) (Applied Imagery, Chevy Chase, MD, USA) designed to easily handle and enhance LiDAR generated terrain models in a 3D environment [46]. QTM facilitates real-time manipulation of large amounts of 3D data, allowing you to surf the model and manipulate the light angle and direction as well as exaggerate the elevation (the z-value) and make digital crosssections of detected anomalies etcetera. Using this approach, the DTM was put through visual analysis as a basis for detecting and identifying anomalies thought to be potential archaeological features. The results from the $2007 / 2008$ study were the basis for the present study but were supplemented by further studies in 2010-2020 (see Figure 5). 
In this period, a new model based on the same dataset with a $25 \mathrm{~cm}$ resolution was built. In addition to traditional hillshade analysis, additional methods were used both for identifying previously unidentified anomalies and structures and refining the visualisation and on-screen identification of these. Methods used were multi-hillshade, slope, skyview factor and openness negative/positive as well as blends of these $[27,47,48]$. The LiDAR data was used to further investigate the detection success by implementing two recently developed visualizing techniques, "Local Relief Model" [26] and "Sky-View-Factor" [24], as additional approaches to analysing and interpreting the data set. The rebuilt DTM was analysed using the visualization techniques "Sky-View-Factor" as well as "Openness positive" and "Openness negative" $[25,28]$ to further explore recent developments in interpretation of DTMs derived from LiDAR. "Sky-view-factor" and "Openness negative/positive" results were both analysed separately as well as overlain with $25-30 \%$ opacity. The latter implementation is in line with Kokalj and Hesse [27].
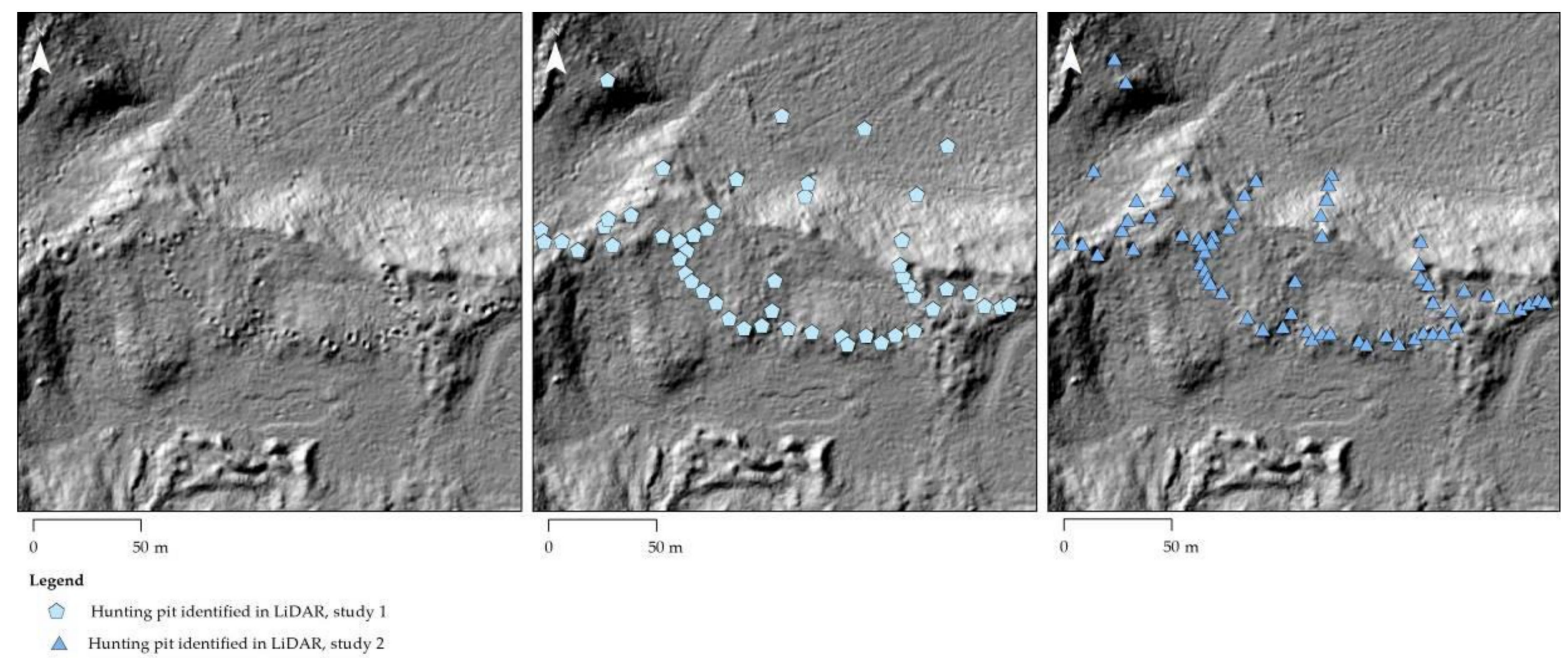

Figure 5. A section of the study area where hunting pits were detected in the LiDAR data, study 1 and 2. The DTM is shown here as a hillshade.

\subsection{Ground Surveys}

Ground surveys were conducted in 2008 in order to verify whether the detected features were in fact cultural heritage, and, if so, to verify the interpretation. They were point-to-point surveys encompassing a selection of the features identified in the LiDAR data, they were not general archaeological surveys of the area. In order to avoid biased data, a random approach was used where every tenth anomaly was systematically investigated as part of the field verification. When the desk-based interpretation was carried out, all anomalies were assigned a unique id. A randomised selection was then made, where all anomalies with 9 as its last figure in the id were chosen: 9, 19, 29, 39, 49 and so on. These were then looked up in the field.

Supplementary field work has been carried out in connection with the second study of the LiDAR data set. The ground truthing efforts were mainly focused on hunting pits and the inland parts of the study area. Other feature types and sites in coastal areas were, to a lesser degree, included to provide a broader set of data as a basis for assessing rate of "right interpretation". A less extensive survey focused on verifying potential dwellings near the coast in the eastern part of the scene. Data from the ground-based surveys were used to assess the rate of "right interpretation", not only for the LiDAR data but also the image data. The assessment of the results from analysing the image data was based on overlapping features, that is, point features placed within $10 \mathrm{~m}$ of each other in both survey data and analysis results and visually interpreted to be the same feature. 


\section{Results}

\subsection{Potential Archaeological Features Identified in the Data}

The results from analysing the LiDAR data and satellite and aerial images vary from 368 features identified as potential cultural heritage based on the aerial images, to 437 and 1186 in the satellite images and LiDAR data, respectively, as shown in Table 4. Moreover, 347 and 380 features were detected in the panchromatic and multispectral satellite images, respectively. The higher number of features detected in the multispectral image reflect the higher number of dwellings detected and identified in this image set. As some features were only detected in either the panchromatic and multispectral image, after merging results and removing double entries, visual analyses of the satellite image data resulted in a total of 437 potential archaeological features. Of the 327 hunting pits identified in the two image sets, there is a $73 \%$ overlap. Although roughly the same number of pits was detected in the two image sets, 89 were only detected in either the panchromatic or the multispectral image. Study 1 of the LiDAR data resulted in the identification of 893 potential archaeological features. The analysis in LiDAR study 2 , which focused on the western part of the scene, resulted in 980 features.

Table 4. Potential archaeological features detected in the LiDAR and image data.

\begin{tabular}{|c|c|c|c|c|c|c|c|}
\hline Data & Hunting Pits & Dwellings & Stone Rings & Mounds & Pits & Structures & All Features \\
\hline Satellite image, panchromatic & 286 & 45 & & & 11 & 5 & 347 \\
\hline Satellite image, multispectral & 284 & 71 & & & 16 & 9 & 380 \\
\hline Satellite image, merged & 327 & 77 & & & 19 & $14^{1}$ & 437 \\
\hline Aerial image & 345 & 10 & & & 5 & 8 & 368 \\
\hline LiDAR, study 1 & 771 & 118 & 3 & 1 & & & 893 \\
\hline LiDAR, study 2 & 980 & & & & & & 980 \\
\hline LiDAR, merged & & & & & & & 1186 \\
\hline
\end{tabular}

${ }^{1}$ Split interpretation; one feature was identified as a structure in the panchromatic image and a dwelling in the multispectral image.

The features detected in all data sets are mostly interpreted as pits, specifically hunting pits for wild reindeer. As can be derived from the results presented in Table 4, hunting pits constitute $75 \%$ of the features identified in the panchromatic and multispectral satellite images and $94 \%$ of the features in the aerial images. In the initial LiDAR study, $86 \%$ of the features were thought to be hunting pits, while in the subsequent study $100 \%$ of the identified anomalies were defined as hunting pits. These pits were detected in high numbers in the western and inland areas of the study area, and many were grouped together and organized in rows forming larger systems as seen in Figure 6.

A number of dwellings were detected in low-lying or coastal areas in the eastern part of the study area. This category encompasses features dating to the Stone Age and Early Metal Age as well as remains of Sámi turf houses, most of which probably are from the 1800 and 1900s. Although it is generally possible to differentiate dwelling sites of varying age through placement and characteristics apparent in the image data, the results listed in Table 4 show the total number to ensure comparability with results based on the LiDAR data. However, it is clear from the aerial and, especially, the satellite images (see Figure 9) that the vegetation in the immediate surrounds of several features interpreted as turf houses has been impacted by human activity over time, possibly indicating long-term settlement. In close proximity to and in conjunction with dwellings, a number of features interpreted as pits and structures of uncertain function were detected. The remaining features listed in Table 4 were identified as stone rings and a mound. 


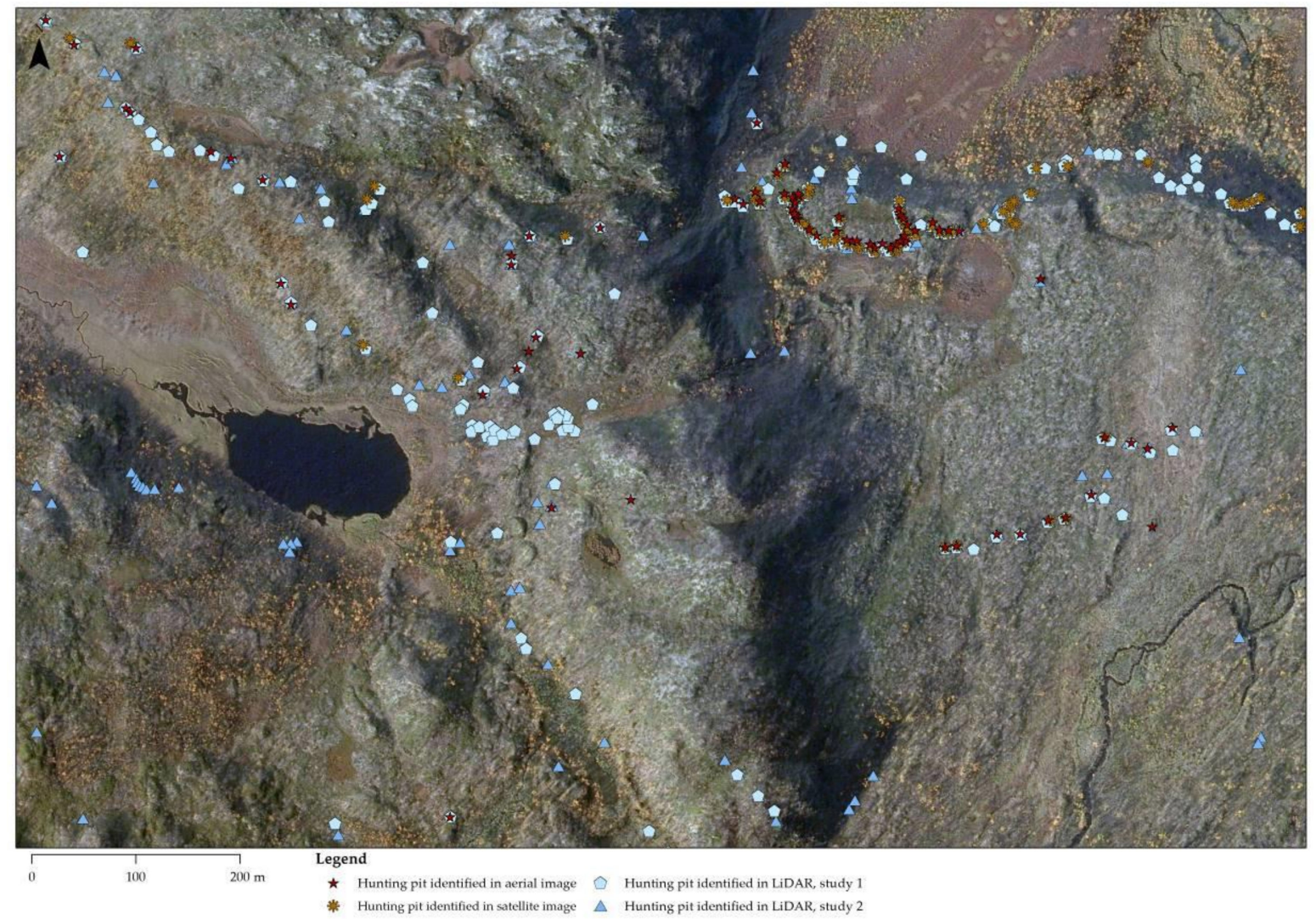

Figure 6. A section of the study area showing hunting pits detected in the LiDAR data and the aerial and satellite images. Image: (CNorwegian Mapping Authority.

\subsection{Verification of the Potential Aarchaeological Features Identified in the Remote Sensing Data Sets}

The results from ground surveys of selected features are presented in Table 5. A total of 139 features were surveyed and identified as either an archaeological feature or a natural occurrence. The surveys were aimed at verifying or "ground-truthing" the results from the analyses but concurrently led to the discovery of archaeological features that the interpretations of the image and LiDAR data failed to identify. Altogether, 40 features, encompassing 20 meat depots, 15 dwellings, three hunting pits and two rectangular structures, were found and mapped during the fieldwork. As the survey was intended to verify the interpretations from the analyses, these new discoveries were "incidental".

Of the surveyed features identified in the initial study of the LiDAR data, 73\% were verified as archaeological features while $27 \%$ turned out to be natural features. As much as $55 \%$ of the features interpreted as dwellings turned out to be natural features, which constitutes $88 \%$ of all misinterpreted features. In comparison, $96 \%$ of the 52 field verified hunting pits were correctly interpreted during the analyses and only two turned out to be natural pits. In the second study of the LiDAR data, the ground truthing of hunting pits showed a success rate of $100 \%$. It should also be noted that the methods used allowed a very clear picture of the respective features. The blending of methods, as suggested by Kokalj and Somrak [47], was particularly effective, more so than manually layering results on top of each other. This included identification of individual features of the hunting pits, in particular the interior shape of the bottom of the pits. 
Table 5. Verification of features detected in the LiDAR and image data.

\begin{tabular}{|c|c|c|c|c|c|c|c|}
\hline Data & Hunting Pits & Dwellings & Stone Rings & Mounds & Pits & Structures & All Features \\
\hline Satellite images & 327 & 77 & & & 19 & $14^{1}$ & 437 \\
\hline Verified features & 19 & 10 & & & 5 & 1 & 35 \\
\hline Verified features; culture & 19 & 10 & & & $3^{2}$ & $1^{2}$ & 33 \\
\hline Verified features; nature & & & & & 2 & & 2 \\
\hline Aerial images & 345 & 10 & & & 5 & 8 & 368 \\
\hline Verified features & 24 & 6 & & & 1 & 3 & 34 \\
\hline Verified features; culture & 23 & 6 & & & $1^{2}$ & $2^{2}$ & 32 \\
\hline Verified features; nature & 1 & & & & & 1 & 2 \\
\hline LiDAR; study 1 & 771 & 118 & 3 & 1 & & & 893 \\
\hline Verified features & 52 & 42 & & 1 & & & 95 \\
\hline Verified features; culture & 50 & 19 & & & & & 69 \\
\hline Verified features; nature & 2 & 23 & & 1 & & & 26 \\
\hline LiDAR; study 2 & 980 & & & & & & 980 \\
\hline Verified & 44 & & & & & & 44 \\
\hline Verified features; culture & 44 & & & & & & 44 \\
\hline Verified features; nature & & & & & & & \\
\hline
\end{tabular}

${ }^{1}$ Split interpretation; one feature was identified as a structure in the panchromatic image and a dwelling in the multispectral image; ${ }^{2}$ One feature was interpreted as dwelling during the ground surveys.

Verification of results from the image analyses showed that $94 \%$ of the features surveyed in both aerial and satellite images were archaeological features. Of the dwellings, $100 \%$ were archaeological features, while the verification rate for hunting pits detected in the satellite and aerial images was $100 \%$ and $96 \%$ respectively.

When returning to the desk to study the models based on the LiDAR data again after the field verification, quite a few of the omitted archaeological features were actually identifiable as such when we were aware of their presence. That was the case with two of the three hunting pits and approximately half of the dwellings that were found during the fieldwork. Some of the surveyed meat depots were detectable as recessions in screes, but these are very hard to distinguish from natural recessions in the same screes.

The detection success was only marginally affected by applying the two additional visualising techniques, "Local Relief Model" and "Sky-View-Factor". The gain was primarily their ability to enhance the visualisation of already identified features. The analysis related to the second LiDAR study where "Openness negative" and "Openness positive" were used as supplemental visualization techniques demonstrated the potential of the method to successfully identify features in areas with steep relief and large differences in slope, as also shown by Doneus [25]. The combination of these methods with "Sky-View-Factor" was very effective for detecting anomalies. However, detection was not dependent on these visualisations as more than half of the detected hunting pits were also visible using hillshading. A consideration is the fact that the reanalysis focused on the western half of the LiDAR dataset. As there is a partially overlapping dataset in this area, data from the second dataset was rebuilt and compared to the results of the dataset under discussion. The results of this analysis did not differ in terms of detection rate. This did, however, demonstrate that the combination of methods used in the reanalysis is robust. The results from the analysis of the overlapping dataset are not included here.

\subsection{Listed Cultural Heritage in the Study Area}

Askeladden, the Norwegian national cultural heritage database, currently contains information on 50 cultural heritage sites encompassing over 400 individual features within the study area [35]. The data have been gathered through traditional means, that is, ground based surveys. Many of the features, especially hunting pits that are a part of larger systems and dwellings located in the large coastal settlement sites, were not individually mapped when the sites were originally surveyed. As an example, one system (Askeladden Id 67178) located in the study area encompassing 55 pits is only mapped as a polygon in the heritage database [35]. The 55 pits are not individually mapped. Comparing our results with the archaeological data available from Askeladden, a significant number of 
previously unlisted or unknown features were detected, as shown in Figure 7. An important distinction, however, is that the sites and features listed in Askeladden are verified cultural heritage. Until verification, the features listed in Table 4 should be considered potential archaeological sites and features.

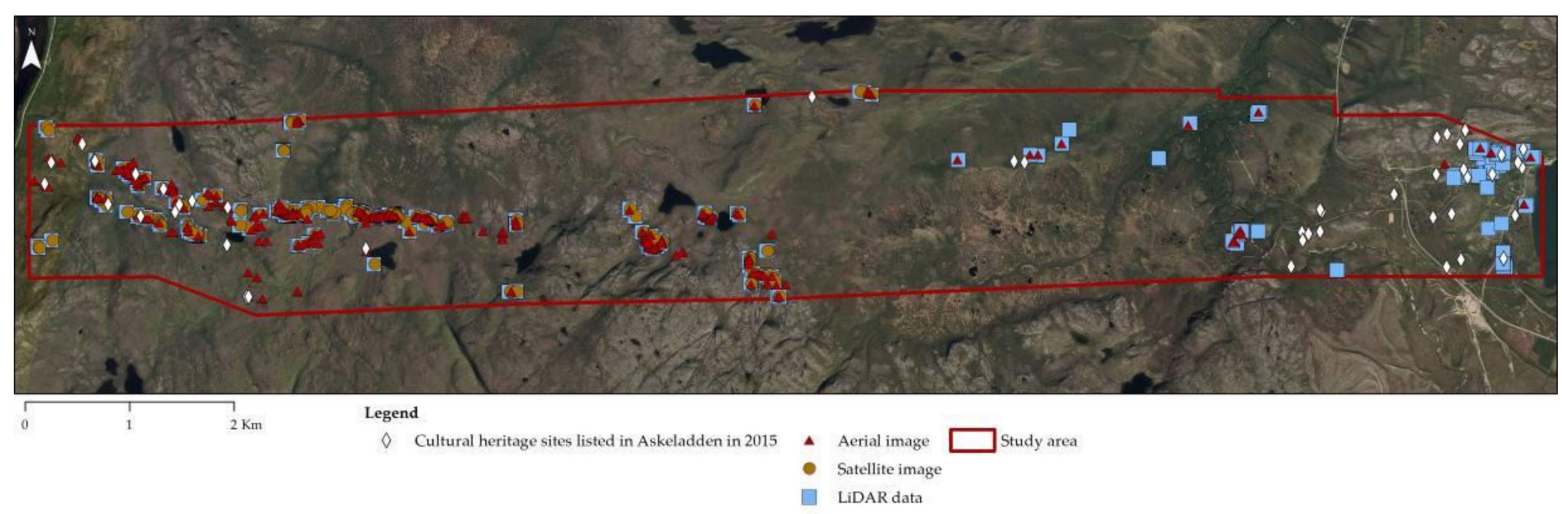

Figure 7. Sites listed in the national cultural heritage database Askeladden prior to this study are significantly outnumbered by the features detected through the LiDAR data and remote sensing images. Image: CNorwegian Mapping Authority.

Field surveys (Table 5) showed that the conducted analyses are quite reliable for hunting pits for both remote sensing image data and LiDAR data. Based on the rate of right interpretation indicated in Table 5, it is also possible to extrapolate a theoretical figure for the number of features. For LiDAR study 1, a $96 \%$ rate of right interpretation indicates that the number of hunting pits within the study area is 740 and the number of dwellings 53 , but that there are no mounds. For LiDAR study 2, the rate is $100 \%$. Further validating the detection rate and consequently the applicability of LiDAR in this landscape, the results from analysing the LiDAR data were a starting point for subsequent surveys conducted by cultural heritage management authorities at Troms and Finnmark County. As shown in Figure 8, there are a far higher number of features listed in Askeladden in 2020 than in 2015. The newly listed features are mostly verified hunting pits.
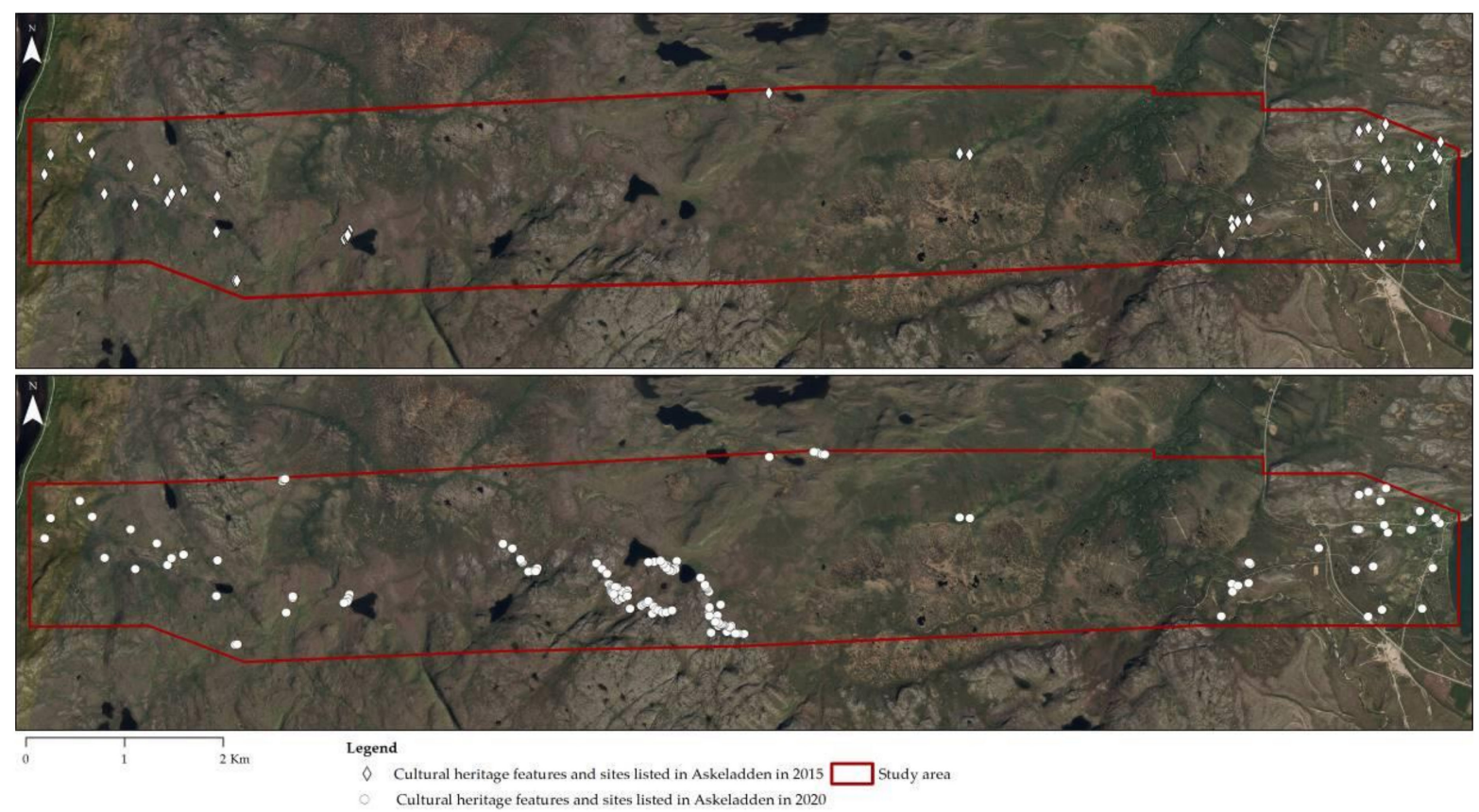

Figure 8. Surveys following the LiDAR studies resulted in a significant increase from 2015 to 2020 in the number of sites and features listed in Askeladden. Image: (Norwegian Mapping Authority. 
When it comes to dwellings as well as the more indefinable structure and pit categorizations, the results are less impressive. Less than half of the verified features identified as dwellings in the DTM were correctly identified (Table 5). On the other hand, the results for the image data were $100 \%$.

\section{Discussion}

5.1. Assessing the Pros and Cons of LiDAR Data, Aerial and High-Resolution Satellite Images for Cultural Heritage Surveying

A starting point for this discussion is the combined results from the analyses listed in Tables 4 and 5. According to these, the DTM yielded a significantly higher number of potential archaeological features compared to both satellite and aerial images. This is especially apparent when it comes to hunting pits. Although the picture is not entirely unequivocal, a substantial number of the hunting pits clearly apparent in the DTM are vague or even non-detectable in the image data as shown in Figure 4. As the suitability of LiDAR regarding hunting pits has previously been proven $[23,45]$, this result is not entirely surprising.

Hunting pits generally form large systems, some of which can consist of hundreds of individual pits. Not only were a larger number of individual pits within systems identified, some smaller systems were only detected through the DTM. Subsequent ground surveys showed that the majority of the detected pits were correctly interpreted. As hunting pits generally are quite uniform circular pits of a regular size and depth, their characteristics mean that LiDAR is highly applicable for detecting this type of archaeological feature. As commented above, the methods used in the analysis of the rebuilt DTM went beyond mere detection. Individual features of the hunting pits could be detected, both the interior shape of the bottom of the hunting pits, as well as features relating to the mounds surrounding them.

The same feature characteristics also proved important when analysing the satellite and aerial images covering the same area. Apart from the regularities in feature characteristics, when hunting pits occur several together in a linear system, as they usually do, they can stand out quite clearly in the images (see Figure 4 for example). Single pits or systems where the pits are located at a distance from each other proved more difficult to identify.

The image analyses and results, especially the distribution of identified pits, indicate that detectability varies with topography and vegetation cover, detectability in this regard is site dependent. Forest and slopes reduce detectability, while hunting pits located in more open and flat landscapes are easier to identify. Vegetation is a critical factor that adversely affects the detection rate when analysing remote sensing images. The option of eliminating vegetation from a dataset by a filtering process is to a great extent the most prominent advantage of using LiDAR. In our case, this is very evident when it comes to detecting hunting pits. The inland parts of the study area are partly covered by birch trees and willow thicket, and the vegetation obscured the visual analyses of the satellite and aerial images.

As Table 5 shows, the ground surveys indicate a high rate of correct interpretation for hunting pits identified in either the LiDAR or image data. The results were not as conclusive regarding potential dwellings. A total of 118, 77 and 10 dwellings were detected in the DTM, the satellite and aerial image data, respectively. However, the rate of correct interpretation is seemingly significantly lower for dwellings than for hunting pits as the field surveys showed $45 \%$ of the verified dwellings detected in the DTM to be correctly interpreted. The image data provided better results in the sense that a higher percentage of the verified features proved to be correctly identified. However, considering what is known from the descriptions of the Stone Age settlement sites [35] within the study area, a rather low percentage of the remaining dwellings was detected through the analyses. Looking at the results, the characteristics of the detected dwellings are a key factor for detectability, both for LiDAR and image data. What is thought to be remainders of walls are generally apparent in either dataset. In addition, quite a few of the Stone Age houses are partly dug down and now appear as circular or rectangular depressions which may or may not be surrounded by a low wall. 
Apart from feature characteristics such as size, shape and depth/height, discernible differences in the vegetation cover aided detectability when analysing the image data. The results from analysing the panchromatic and multispectral satellite images showed some differences in detection rate. Although the multispectral image provided a slightly higher number of potential features than the panchromatic image, the most notable differences are related to type of feature. The multispectral image provided somewhat better results regarding potential dwellings, pits and other structures linked to settlement sites. Dwelling remains constitute $19 \%$ of the features in the multispectral image and $13 \%$ of the features identified in the panchromatic image (Table 4). The difference is especially notable when it comes to features located in arable land near the coast. Of the 77 identified dwellings, 39 were detected in only one image. A total of 327 hunting pits were identified in the two image sets. Although nearly the same number of pits was detected in the two image sets and a substantial number of these pits overlap, 89 were only detected in either the panchromatic or the multispectral image.

Running two band combinations, one including the NIR1-band, proved advantageous for detecting and identifying dwellings. As previously mentioned, the NIR1-R-G bands allows for vegetation and variations in vegetation linked to type and condition to be detected. The band combination proved useful for detecting areas where the vegetation had been impacted by human activity, where features such as dwelling remains subsequently were detected. Vegetation and variations in the vegetation cover proved useful for detecting potential features and for determining where to look for archaeological features. This was especially true for the more recent traces of Sámi activity and settlement. Sámi settlement areas may show up quite clearly, as shown in Figure 9 where a large rectangular structure interpreted as a potential turf house of about $12.5 \times 6 \mathrm{~m}$ was detected in a clearing. It is worth noting that, although this structure was very apparent in the multispectral image and quite easily detectable in the panchromatic image, as can be seen in Figure 9, it was not detected when interpreting the DTM. As this site was not among those surveyed during the field work, it is unclear whether feature characteristics play a role in detectability. As for hunting pits, running the RGB band combination alone proved adequate. The past activities affiliated with reindeer hunting have not left an easily detectable imprint on the vegetation in and around the pits.

Of the detected dwellings, 38 are part of extensive Stone Age settlements located near the coast. For these dwellings, vegetation differences generally seem less distinctive than for the more recent Sámi dwelling remains. The exception was the walls of features located in what is now arable grassland, which appeared somewhat highlighted compared to the surrounding area in the images. The vegetation on and around features which are not located in what is or has recently been agricultural areas does not appear to similarly "enhance" heritage features. Regardless, some dwellings were quite apparent in the images, most of which were found in coastal areas or near rivers in more inland low-lying areas. The disadvantages of a dense vegetation cover when analysing image data were less apparent as most dwelling remains are located in coastal areas, in what is now agricultural areas or cleared settlement areas. Along the coast of northernmost Norway, forest and shrubs are generally sparse or absent, leaving the landscape open and covered by grass and heath. This together with the fact that dwellings that are several thousand years old are still visible on the surface argues for the viability of image data in these areas. 

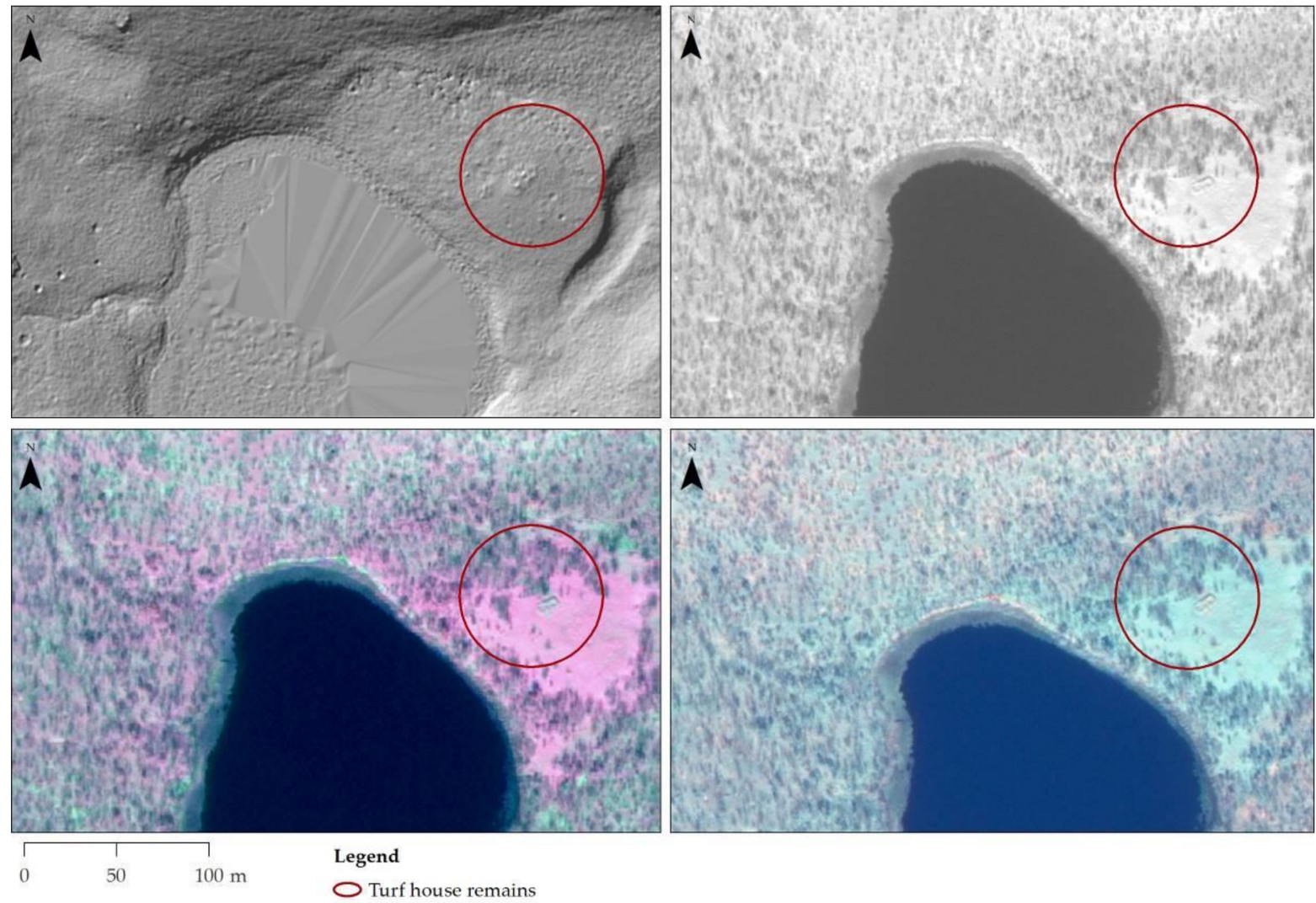

Figure 9. The remains of a rectangular turf house is located within the area outlined in red. The dwelling is detectable in the panchromatic and multispectral satellite images. The panchromatic image is on the top right, while the multispectral image is shown on the bottom row with the bands NIR1-R-G on the left and R-G-B on the right. In the LiDAR data on the top left, the remains are not identifiable as a turf house. Note, however, the highly visible hunting pits on the left in the figure. Images: @Digital Globe.

5.2. The Applicability of LiDAR and Remote Sensing Image Data for Archaeological Surveying in the Subarctic and Arctic Landscapes of Northern Norway

This study has shown that LiDAR and aerial and satellite images are highly applicable and useful for archaeological surveying in northern subarctic and arctic landscapes. The results have contributed to improve the inventory of known archaeological sites and features throughout the region. At the same time, the analyses and results also show that there are some limitations.

The listed cultural heritage sites within the study area represent various aspects of hunting and gathering, settlement and subsistence as well as religious beliefs and practices from the Early Stone Age into modern times. The national database [35] lists several hunting pit systems (some of which consist of up to around 50 pits), meat depots, aggregations of up to 50 house sites dating to the Stone Age, Stone Age artefact scatters (surface finds), Sámi turf houses, hearths (arran) (of which many are related to reindeer husbandry) and Sámi sacrificial sites. In comparison, our study yielded a limited number of cultural heritage types. Our analyses provided data on mainly two types of archaeological features, hunting pits for reindeer and dwellings, the last category encompassing features dating to the Stone Age and Early Metal Age as well as more recent centuries. To some extent this reflects local cultural history and existing cultural heritage data. The high number of detected hunting pits reflects the fact that hunting pit systems are known to be numerous in this area and is indicative of the importance of reindeer hunting for subsistence and economy in prehistoric and historic times. However, our results did not provide a general representation of cultural heritage sites in the area. 
Our study showed remote sensing to be ill-suited for many of the feature types known to be found in this region. Hunting pits and dwellings are both archaeological features that are, comparatively speaking, quite sizable and of uniform design. A range of features linked to Sámi resource and landscape use, are in many cases anything but monumental and often blend in well with the landscape. The most visible remains of Sámi reindeer husbandry camp sites are often the stones delineating the hearths. Meat depots, which are often located in screes, appear as one depression among many and were indistinguishable from the surrounding area in both the DTM and image data. Stone Age activity and settlement areas have in many cases been located through surface artefact scatters which, so far, are undetectable by LiDAR and aerial and satellite remote sensing image data. However, as sites in this area often encompass a range of features, the results may contribute to narrow down the search area and provide a useful indicator of where to conduct further studies and ground surveys. A good example are the point-to-point surveys to selected detected features which also resulted in the discovery of another 40 archaeological features that the analyses of the image and LiDAR data failed to identify. Another example is the dwellings detected in coastal areas where extensive Stone Age settlements are known to be located. The fact that utilising LiDAR and remote sensing image data is shown to be applicable for narrowing down and consequently prioritising search areas is an important argument in favour of integrating such data and methodological approaches in archaeological surveying as they may contribute towards remote and hard-to-get-to areas being surveyed in a lowimpact and cost-efficient manner. Interpretation of images and a DTM based on visual analyses aided by processing and visualizing techniques is time-consuming but compared to the often much more time-consuming and costly field work, well worth the effort in these areas.

As mentioned above, the national database lists several hunting pit systems of varying size within the study area. Earlier surveys in the area generally mapped the extent of the systems and provided an approximate number of pits, but individual features were seldom mapped. This is also the case for several of the Stone Age settlement sites in the area. As the remote sensing data have been used to map individual features, they provide a valuable addition to already listed sites, especially for hunting pit systems where the rate of right interpretation is high. Remote sensing methods can thus add reliable and valuable detailed information of individual features within an archaeological site.

Visual interpretation, as used in this study, is a qualitative and seemingly simple process. Its main advantage compared to digital data processing is the fact that it can be carried out also when object features are not easily distinguishable [12]. However, in order to recognize patterns and characteristics, to extract meaningful data through visual analyses, features have to be identified and allocated into known categories. The practical and realistic use-value of LiDAR data and remote sensing image data is dependent on local conditions pertaining to surface conditions such as topography and vegetation cover, the characteristics of archaeological features and site characteristics such as size, depth/height, uniformity, building materials, placement and, not least, what we expect to find within a given area. Familiarity with cultural history, feature type characteristics and localization factors are of importance when conducting the analyses. As an example, hunting pits for reindeer and remains of Sami reindeer husbandry are within expectations for this area, consequently the data is searched for features with characteristics in line with what is known of archaeological features like hunting pits. Hunting pits generally occur in systems so once one or two potential pits are detected, one will generally detect more in the vicinity. If the interpreter is unaware that large-scale hunting of reindeer was based on hunting pit systems, a pit may very well be dismissed as a pit.

Current knowledge and understanding of the area's tangible cultural history is primarily based on ground-based surveys. Our study resulted in a high number of potential archaeological features far exceeding current knowledge and existing listed sites in the national cultural heritage database. Our analyses of aerial and satellite images as well as LiDAR data have shown potential, especially when combining results from the two sets of 
remote sensing data. The advantages of a multi-sensor approach can be instrumental in improving current knowledge. In our case, the LiDAR data provided better results for the more vegetated inland areas, while the satellite images proved useful for detecting sites based on human inflected changes in the vegetation.

\section{Conclusions}

What can remote sensing contribute to archaeological surveying in subarctic and arctic landscapes? We have proven remote sensing utilizing LiDAR data and image data to be highly applicable for archaeological surveying in these northern landscapes. This study has led to the identification of 368 cultural heritage features based on aerial images, 437 on satellite images and 1186 based on a DTM covering the study area. Furthermore, ground surveys following the studies have resulted in a significant increase in the number of sites and features listed in the national cultural heritage database, Askeladden. We have shown that a multi-sensor approach contributes to high detection rates and thus can be instrumental in improving current knowledge. At the same time, our results showed that there are limitations. Feature characteristics, topography and vegetation cover proved key factors for detectability. LiDAR and remote sensing image data were shown to be ill-suited for some of the feature types common throughout the region. Even so, the results proved a useful indicator of where to focus attention and further survey activities.

We have contributed to improving the inventory of known archaeological sites in a subarctic and arctic landscape in a non-destructive and minimally invasive manner. A better overview of the archaeological remains in a landscape is crucial for a qualified cultural historical understanding of how the landscape was utilized by humans in the past. Furthermore, it is a precondition for optimizing cultural resource management and for sustainable cultural heritage management. Apart from the value of remote sensing for improving knowledge and understanding about the past and for efficient improvement of data quantity and quality, there is the additional value of remote sensing as a non-invasive means of mapping and monitoring cultural heritage. Considering the vast and hard-to-getto areas, especially in the north of Norway and other northern areas, the substantial costs and potential environmental impact associated with traditional archaeological surveying are a significant inducement to the current focus on further exploring the potential of remote sensing technologies. To further improve the applicability of remote sensing, a fruitful avenue for further research would be to focus on methodological development aimed at detecting and identifying a wider range of the cultural heritage sites and features commonly found throughout the region.

Author Contributions: Conceptualization, A.E.T.; methodology, A.E.T., O.R. and J.I.K.; validation, A.E.T., O.R. and J.I.K.; E.R.M.; formal analysis, A.E.T., O.R. and J.I.K.; investigation, A.E.T., O.R. and J.I.K.; writing-original draft preparation, A.E.T., O.R. and J.I.K., S.B.; writing-review and editing, A.E.T.; visualization, A.E.T.; supervision, A.E.T.; project administration, O.R., A.E.T.; funding acquisition, O.R. and E.R.M. All authors have read and agreed to the published version of the manuscript.

Funding: This research was funded by The Research Council of Norway, Bruk av avansert teknologi for å kartlegge, forstå, konservere og forvalte kulturarven, grant number 208439 of which this study was a part.

Institutional Review Board Statement: Not applicable.

Informed Consent Statement: Not applicable.

Data Availability Statement: The data presented in this study are available on request from the corresponding author, the second and third co-author.

Acknowledgments: The authors would like to thank colleagues at NIKU's High North Department for constructive feedback. Three anonymous reviewers are kindly acknowledged for helpful comments which contributed to improve this paper. 
Conflicts of Interest: The authors declare no conflict of interest. The funders had no role in the design of the study; in the collection, analyses, or interpretation of data; in the writing of the manuscript, or in the decision to publish the results.

\section{References}

1. Nummedal, A. Stone Age Finds in Finnmark; Institutt for Sammenlignende Kulturforskning: Oslo, Norway, $1929 ;$ Volume B13.

2. Gjessing, G. Yngre Steinalder i Nord-Norge; Institutt for Sammenlignende Kulturforskning: Oslo, Norway, $1942 ;$ Volume B39.

3. Gjessing, G. Fra Steinalder til Jernalder i Finnmark; Institutt for Sammenlignende Kulturforskning: Oslo, Norway, 1935; Volume 3:3.

4. Barlindhaug, S.; Risan, T.; Thuestad, A.E. Kulturhistoriske Registreringer. Porsangermoen-Hálkavárri Skytefelt; NIKU: Tromsø, Norway, 2007.

5. Parcak, S.H. Satellite Remote Sensing for Archaeology; Routledge: Abingdon, UK, 2009.

6. Skjelsvik, E. Registrering av Fornminner for det Økonomiske Kartverket 1963-1994; Norsk Institutt for Kulturminneforskning: Oslo, Norway, 1998; Volume 25.

7. Barlindhaug, S.; Holm-Olsen, I.M.; Tømmervik, H. Monitoring archaeological sites in a changing landscape-using multitemporal satellite remote sensing as an "Early Warning" method for detecting regrowth processes. Archaeol. Prospect. 2007, 14, 231-244. [CrossRef]

8. Barlindhaug, S.; Holm-Olsen, I.M. From pixels to prognoses Space age technology in the service of cultural history. In Kulturminner en Ressurs i Tiden; Paludan-Müller, C., Gundhus, G., Eds.; NIKU: Oslo, Norway, 2005; pp. $24-33$.

9. Tømmervik, H.; Dundjeld, S.; Olsson, G.A.; Nilsen, M.Ø. Detection of ancient reindeer pens, cultural remains and anthropogenic influenced vegetation in Byrkije (Børgefjell) mountains, Fennoscandia. Landsc. Urban Plan. 2010, 98, 56-71. [CrossRef]

10. Hritz, C. Contributions of GIS and satellite-based remote sensing to landscape archaeology in the Middle East. J. Archaeol. Res. 2014, 22, 229-279. [CrossRef]

11. Lillesand, T.M.; Kiefer, R.W.; Chipman, J.W. Remote Sensing and Image Interpretation, 6th ed.; Wiley: Hoboken, NJ, USA, 2008.

12. Masini, N.; Lasaponara, R. Satellite Remote Sensing: A New Tool for Archaeology; Springer: Dordrecht, The Netherlands, 2012; Volume 16.

13. Giardino, M.; Haley, B.S. Airborne remote sensing and geospatial analysis. In Remote Sensing in Archaeology: An Explicitly North American Perspective; Johnsen, J.K., Ed.; The University of Alabama Press: Tuscaloosa, AL, USA, 2006.

14. Lasaponara, R.; Masini, N. Satellite remote sensing in archaeology: Past, present and future perspectives. J. Archaeol. Sci. 2011, 38, 1995-2002. [CrossRef]

15. Trier, Ø.D.; Brun, T.A.; Gustavsen, L.; Kristensen, S.; Larsen, S.Ø.; Salberg, A.-B.; Solberg, R.; Stomsvik, K.H.; Tonning, C. Application of Satellite Data in Management of Cultural Heritage; Project Report 2008; Norwegian Computing Center: Oslo, Norway, 2010.

16. Trier, Ø.D.; Larsen, S.Ø.; Solberg, R. Automatic detection of circular structures in high-resolution satellite images of agricultural land. Archaeol. Prospect. 2009, 16, 1-15. [CrossRef]

17. Trier, Ø.D.; Pilø, L.H. Automatic detection of pit structures in airborne laser scanning data. Archaeol. Prospect. 2012, 19, 103-121. [CrossRef]

18. Beck, A.; Philip, G.; Abdulkarim, M.; Donoghue, D. Evaluation of Corona and Ikonos high resolution satellite imagery for archaeological prospection in western Syria. Antiquity 2007, 81, 161. [CrossRef]

19. Doneus, M.; Briese, C. Airborne laser scanning in forested areas-potential and limitations of an archaeological prospection technique. In Heritage Management of Farmed and Forested Landscapes in Euro; EAC Occasional Paper No. 5; European Archaeological Council: Namur, Belgium, 2011.

20. Risbøl, O.; Langhammer, D.; Schlosser Mauritsen, E.; Seitsonen, O. Employment, utilization, and development of airborne laser scanning in fenno-scandinavian archaeology-A Review. Remote Sens. 2020, 12, 1411. [CrossRef]

21. Risbøl, O.; Bollandsås, O.M.; Nesbakken, A.; Ørka, H.O.; Næsset, E.; Gobakken, T. Interpreting cultural remains in airborne laser scanning generated digital terrain models: Effects of size and shape on detection success rates. J. Archaeol. Sci. 2013, 40, 4688-4700. [CrossRef]

22. Gallagher, J.M.; Josephs, R.L. Using LiDAR to detect cultural resources in a forested environment: An example from Isle Royale National Park, Michigan, USA. Archaeol. Prospect. 2008, 15, 187-206. [CrossRef]

23. Risbøl, O. Towards an improved archaeological record through the use of airborne laser scanning. In Space, Time and Place. Proceedings of the 3rd International Conference on Remote Sensing in Archaeology, Tiruchirappalli, India, 17-21 August 2009; Forte, M., Campana, S., Liuzza, C., Eds.; Archaeopress: Oxford, UK, 2010; Volume 2118, pp. 105-112.

24. Kokalj, Z.; Zaksek, K.; Ostir, K. Application of sky-view factor for the visualisation of historic landscape features in lidar-derived relief models. Antiquity 2011, 85, 263. [CrossRef]

25. Doneus, M. Openness as visualization technique for interpretative mapping of airborne lidar derived digital terrain models. Remote Sens. 2013, 5, 6427-6442. [CrossRef]

26. Hesse, R. LiDAR-derived Local relief models-A new tool for archaeological prospection. Archaeol. Prospect. 2010, 17, 67-72. [CrossRef]

27. Kokalj, Ž.; Hesse, R. Airborne Laser Scanning Raster Data Visualization: A Guide to Good Practice; Založba ZRC: Ljubljana, Slovenia, 2017. [CrossRef] 
28. Štular, B.; Kokalj, Ž.; Oštir, K.; Nuninger, L. Visualization of lidar-derived relief models for detection of archaeological features. J. Archaeol. Sci. 2012, 39, 3354-3360. [CrossRef]

29. Challis, K.; Forlin, P.; Kincey, M. A generic toolkit for the visualization of archaeological features on airborne LiDAR elevation data. Archaeol. Prospect. 2011, 18, 279-289. [CrossRef]

30. Bennett, R.; Welham, K.; Hill, R.A.; Ford, A. A comparison of visualization techniques for models created from airborne laser scanned data. Archaeol. Prospect. 2012, 19, 41-48. [CrossRef]

31. Norwegian Institute of Bioeconomy Research (NIBIO). AR50 Land Resource Map; Norwegian Institute of Bioeconomy Research (NIBIO): Ås, Norway, 2016.

32. Kleppe, J.I. Desolate landscapes or shifting landscapes? Late glacial/early post-glacial settlement of northernmost Norway in the light of new data from Eastern Finnmark. In BAR International Series; Riede, F., Tllaavaara, M., Eds.; Archaeopress: Oxford, UK, 2014; pp. 121-145.

33. Kleppe, J.I. The pioneer colonisation of Northern Norway. In Early Economy and Settlement in Northern Europe: Pioneering, Resource Use, Coping with Change; Blankholm, H.P., Ed.; Equinox Publishing: Sheffield, UK, 2018; Volume 3, pp. $13-57$.

34. Olsen, B. Bosetning og Samfunn i Finnmarks Forhistorie; Pensumtjeneste: Oslo, Norway, 1997.

35. Askeladden. Norwegian Directorate for Cultural Heritage. Available online: https://askeladden.ra.no/Askeladden/ (accessed on 11 December 2020).

36. Halinen, P. Prehistoric Hunters of Northernmost Lapland: Settlement Patterns and Subsistence Strategies; Finnish Antiquarian Society: Helsinki, Finland, 2005.

37. Furset, O.J. Fangstgroper og Ildsteder i Kautokeino Kommune. Rapport fra Forskningsgraving 24 Juli-3 September 1994; University of Tromsø: Tromsø, Norway, 1995.

38. Furset, O.J. Fangstgroper i Karasjok Kommune: Rapport fra Forskningsutgraving 3 Juli-4 August 1995; University of Tromsø: Tromsø, Norway, 1996.

39. Mulk, I.-M. Sirkas-ett samisk fångssamhälle i förändring Kr.f.-1600 e.Kr.; Umeå University: Umeå, Sweden, 1994.

40. Vorren, Ø. Villreinfangst i Varanger fram til 1600-1700 Årene; Tromsø Museums Skrifter; Nordkalott Forlaget: Finnsnes, Norway, 1998; Volume 28.

41. Myrvoll, E.R.; Thuestad, A.E.; Holm-Olsen, I.M. Wild reindeer hunting in arctic Norway: Landscape, reindeer migration patterns and the distribution of hunting pits in Finnmark. Fennosc. Archaeol. 2011, 28, 3-17.

42. Odner, K. Trade, tribute and household responses. The archaeological excavations at Geah evájnjarga 244 B in the Varangerfjord, Northern Norway. Acta Boreal. 2001, 18, 25-50. [CrossRef]

43. Hansen, L.I.; Olsen, B. Samenes Historie Fram til 1750; Cappelen Akademisk Forlag: Oslo, Norway, 2004.

44. Norge i Bilder. Available online: https:/ / www.norgeibilder.no/ (accessed on 8 December 2020).

45. Risbøl, O. Flybåren Laserskanning av Kulturminner ved Gollevarre, Tana og Nesseby Kommuner, Finnmark Fylke; NIKU: Oslo, Norway, 2009.

46. Quick Terrain Modeler. Available online: http://appliedimagery.com/ (accessed on 11 December 2020).

47. Kokalj, Ž.; Somrak, M. Why not a single image? Combining visualizations to facilitate fieldwork and on-screen mapping. Remote Sens. 2019, 11, 747. [CrossRef]

48. Zakšek, K.; Oštir, K.; Kokalj, Ž. Sky-View factor as a relief visualization technique. Remote Sens. 2011, 3, 398-415. [CrossRef] 